Marga reth Rago

Universidade Esta dual de Campinas

\title{
Novos modos de subjetivar: a experiência da organização Mujeres libres na Revolução Espanhola
}

Resumo: Focalizo, neste texto, a experiência de um dos maiores movimentos femininos de massas durante a Revolução Espanhola, o grupo anarc ofeminista Mujeres Libres, tendo como referências teóricas a crítica feminista e os conceitos foucaultianos relativos à ética e à subjetividade. No âmbito do movimento revolucionário que se deflagra na Espanha dos anos trinta, essa organiza ção lutou pela a utonomia feminina, entendendo claramente a nec essidade de criar novos modos de subjetivação num país altamente conservador, religioso e machista. Palavras-chave: feminismo; Foucault; anarquismo; estéticas da existência; cuidados de si.

Copyright a 2008 by Revista Estudos Feministas.

\begin{abstract}
Dissemos, outro dia, que a Revolução devia começarem nós mesmos, e se não o fizermos, perderemosa Revolução social, nem mais, nem menos; nossa mentalidade burguesa não fará mais do que revestir de roupas novas os velhos conceitos, conservando-osem toda sua integridade.

Lucía SanchezSa omil
\end{abstract}

\footnotetext{
${ }^{1}$ FOUC AULT, 1985a.
}

Estudos recentes destacam a importância de historic iza rem-se as práticas volta das para a produção de outra s sub jetivida des, desenvolvid a s em diferentes contextos históric os. Nessa direção, as "téc nic as de si" ela bora das no mundo greco-romano, como bem percebeu Michel Foucault, diferiam profundamente dos modos de constituição de si promovidosna modemidade, já que não se pautavam pelo acento sobre os padrões normativos de sujeição, tão recorrentes na moral burguesa, porém, tão pouco questionados. ${ }^{1}$ Ao contrário do ideal de formação do indivíduo higiênic 0 , obediente e sub misso, os a ntig os gregos 
${ }^{2}$ Ana Carolina de Toledo MURGEL, 2007; Luana Saturnino TVARDOVSKAS, 2007; e Maria Clara Pivato BIAJ OLI, 2007. investiam na criação de indivíduos livres e temperantes, capazes de autogovemo e, por conseguinte, capazes ta mbém de govema ro outro. Partic ipar da polis implic ava um govemo de si, que não significava a repressão dos desejose dos prazeres, mas sim a virtude da temperança, da qualida de de quem não se torna va vítima das paixões, embora fizesse um bom "uso dosprazeres".

No terreno dos estudos históricos, o eco dessas discussões se faz sentir. Não foi ta refa fácil desfazer-se das noções de essência e natureza humana, tão fortemente ancoradas no imaginário social, e problematizar a historicidade do sujeito. No caso dos estudos feministas, muitas pesquisas desvendaram as ardilosas estratégias de produção normativa da figura feminina pelos discursos médic ose juríd ic os, extrema mente moralista se conserva dores, assim como pela literatura e pela propaganda. Ainda são poucas, contudo, as que investigam as experiências históric as de "invenção de si" das mulheres, especia Imente quando saímos da área da literatura. ${ }^{2}$

Aqui, não se trata a penas das novas sociabilidades diferenciadas com que as mulheres se articularam e puderam escapardas redes do poder, em várias épocas. Trata-se, sobretudo, da maneira pela qual subverteram a ordem moral no mais íntimo de seu ser, isto é, na maneira pela qual construíram a si mesmas, olhando-se de maneira independente do olhar masculino projetado sobre elas e, por conseguinte, de como puderam estabelecer novas relações com a/o outra/o. Está em jogo, nesse sentido, ao referir-se às "estétic as da existência", a pergunta pelo modo como as mulheres contribuíram e contribuem para a construção de novos va lores e códigos éticos, ajudando a atua liza ro imaginário político e cultural de seu tempo.

Se deslocamentos e transformações subjetivas são experiências pessoais que as mulheres têm realizado pratic a mente nasúltima squatro décadas, as elaborações e as discussões teóricas que suscitam avançam mais lentamente, fora da psicanálise e da psicologia. Novamente, à exceção de excelentes trabalhos realizados na á rea literária, pouco sa bemos de um rico e positivo passa do em que as mulheres lutaram para escapar das redes de captura do Estado e do poder masculino no terreno da subjetivação, isto é, da produção de sua própria subjetividade. Énessa direção que situo esta pesquisa sobre o grupo a na rc ofeminista Mujeres Libres, e é uma reflexã o em torno deste trabalho e dos pressupostos teóricos que o norteiam que proponho brevemente neste texto. 
${ }^{3}$ FOUCAULT, 1985a e 1985b.

${ }^{4}$ FOUCAULT, 1985a e 1985b, p. 15 .

${ }^{5}$ FOUCAULT, 1985a e 1985b, p. 82.

${ }^{6}$ FOUCAULT, 1977.

\section{Práticas da liberdade}

Para essa reflexão, é inevitável retomar Foucault, já que são as suas problematizações e os conceitos que constrói que permitem olhardiferentemente para o passa do e elaborá-lo, buscando nã o o que fomosna origem, a partir da linha da continuidade histórica que legitima o nosso presente, mas perguntando, numa perspectiva genealógica, pelas descontinuidades, pelas diferenças que nos separam dos antepassados. Aliás, foi o que ele próprio fez a o voltar-se para a história da Antigüidade greco-romana, nos volumes 2 e 3 de sua História da sexualidade, em que visa conhecera maneira como osantigospraticaram outros modos de subjetivação e de forma ção do cida dão, criando suas "artes da existência". ${ }^{3}$ Vale lembrar que, para esse filósofo, as "a rtes da existência", ou "téc nic as de si", podem ser definidas como

práticas refletidas e voluntárias a través das qua is os homens não somente se fixam regras de conduta, como também procuram se transformar, modificarse em seu ser singular e fazer de sua vida uma obra que seja portadora de certos valores estéticos e responda a certos critérios de estilo. ${ }^{4}$

Em outra passagem, explicando que os gregos não entendiam o conhecimento de si como uma revelação de alguma essência alojada no fundo de si mesmo, nem visavam alcançar uma verdade pessoal a partir da decifração de si e de uma hermenêutica do sujeito, Fouc ault afirma que por "estética da existência"

deve-se entender [...] uma maneira de viver cujo valor moral não está em sua conformidade a um código de comportamento nem em um trabalho de purificação, mas depende de certas formas, ou melhor, certos princípios forma is gerais no uso dos prazeres, na distribuição que deles se faz, nos limites que se observa, na hierarquia que se respeita. ${ }^{5}$

Entende-se, pois, que em sua tenta tiva de traçaruma "genealogia da alma moderna", a pós estudar, na História da sexualidade: a vontade de saber, ${ }^{6}$ os procedimentos disc ip lina res desenvolvidos na modemida de, tenha partido em busca de outros modos de constituição de si, radica Imente diferentes daqueles que conhecemos. Afinal, a moral burguesa a presenta-se como verdadeira e universal, valendo para qualquer classe social, grupo étnico ou gênero, definindo a vida de cada um e de todos de ponta a ponta. Assim, muito distante da experiência moderna, Fouc a ult enc ontra, em nosso passa do oc id ental, mora is que não se destina ra m a sujeitaro indivíduo, a produzir "corpos 
7 FOUCAULT, 1994, T. IV, p. 1.531.

${ }^{8}$ Frédéric GROS, 2006, p. 137. dóceis", fazendo-o renunciar a si mesmo, como prega o cristia nismo. No mundo antigo, evidenciam-se outros modos de subjetivar, a invenção de outros estilos de vida em que a preoc upação maioré a da ordem da ética e da liberdade, e não da submissã o e do poder. Mostrando modos diferentes e estiliza dos de existir, esse filósofo a ponta para as técnicas de si do mund o greco-romano como "práticas da liberdade", exercidas na relaçã o consigo e constituídas por exercícios que a sociedade oferecia e ensinava como maneiras de formar autonomamente o cidadão, educar o jovem na a prendiza gem do "c uida do de si" e na rela ção com o outro. Segundo ele,

[...] para os Gregos e Romanos, - sobretudo para os gregos, - para bem se conduzir, para praticar como se deve a liberdade, era preciso ocupar-se de si, preocupar-se consigo mesmo, a o mesmo tempo para conhecer-se [...] e para formar-se, para superar-se a si mesmo, para dominar em si os apetites que a meaçariam levá-lo. ${ }^{7}$

Foucault insiste, portanto, em mostrar como o conhecimento de si, entendido como uma busca do que existe de verda deiro no fundo de nós mesmos, não é um a to neutro, mas uma forma de submissão a o olhar do outro, já que se estabelece, como explica o filósofo Frédéric Gros, "uma solidarieda de históric a entre a constituição de si como objeto de conhecimento por si mesmo, a obediência ind efinida a o Outro e a morte perpétua para si mesmo". ${ }^{8}$ Ao mesmo tempo, ele abre a possibilidade de problematiza ra reinvenção de si a o pensar a subjetivida de como históric a e não natural, como uma construção e não como uma determina ção biológ ic a ou cultural ine vitá vel, c omo a firmou o século XIX e a ceitou grande parte do século XX.

Dardesta que a o tema do "cuidado de si" tal como é problematizado na cultura greco-romana adquire, na a tua lida de, um sig nific a d o polític o maior, pois se trata, nessa "conversão" - e não "renúncia de si" -, da possibilidade das rebeldias e das resistências, dos deslocamentos, das mudanças, do ser outro/a do que se é, tanto quanto da a mizade, da invenção de novos laços socia is não regidos pelo desejo de podere de hierarquização.

Em se tratando desse universo de questões, é importante observarque o feminismo ta mbém rompe com a tra diçã o oc id ental a o revela rque a s mulheres são ca pazes não a penas de realizar as tarefas masculinas, desempenhando com competência as funções correntes da esfera pública, mas que podem revolucionar as relações socia is, criando novos parâmetros para pensara a mizade. Solidário com essa luta, Foucault sabia bem que as mulheres trazem 
um enorme potencial criado a partir de suas difíceis experiências de vida, experiências de exclusão, op ressão, humilhação e marginalização. Como diz ele,

Eu diria também, no que diz respeito ao movimento lésbico, em minha perspectiva, que o fato de que as mulheres tenham sido por séculos e séculos isoladas na sociedade, frustradas, desprezadas de várias maneiras thes proporcionou uma possibilidade real de constituir uma sociedade, de criar um tipo de relação social entre elas, fora de um mundo dominado pelos homens. ${ }^{9}$

Ao mesmo tempo, numa passagem rápida de $A$ hermenêutica do sujeito, reconhece a existência de inúmeras tentativas históricas de fundação de um novo sujeito étic o e de novos espaçospolític ose sociais. Em suas palavras:

[...] podemos reler toda uma vertente do pensamento do século XIX como a difícil tenta tiva, ou uma série de difíc eis tentativas, para reconstituir uma ética e uma estética do eu. Tomemos, por exemplo, Stirner, Schopenhauer, Nietzsche, o dandismo, Baudelaire, a anarquia, o pensamento anarquista, etc., e teremos uma série de tentativas [...] polariza das pela questão: é possível constituir, reconstituir uma estética e uma ética do eu? A que preço e em que condições? Ou entã o: uma ética e uma estética do eu não deveriam finalmente inverter-se na recusa sistemática do eu? [...] constituir hoje uma ética do eu, tarefa urgente, fundamental, politicamente indispensável, se for verdade que, afinal, não há outro ponto, primeiro e último de resistência ao poder político senão na relação de si para consigo. ${ }^{10}$

${ }^{10}$ FOUCAULT, 2004, p. 305.

A pergunta que, então, move-me ao estudar a experiência histórica do grupo Mujeres Libres, muito a tivo durante a Revolução Espanhola, visa às interpretaçõese às práticas que essa s a na rc ofeminista s cria ram na produção de novas subjetivida dese na construção de modos libertánios de existência, num momento de profunda tra nsformação socioeconômica e polític a. Perg unto como o a na rquismo e o feminismo permitiram enfrenta $r$, discutir e pôr em prática, na quele contexto históric o revoluc ionário, a criação de novos modos de existência a partir da ética a firmada por essas doutrinas.

\section{Mujeres Libres, da Espanha}

A organiza ção Mujeres Libres surge na Espanha pela iniciativa de três anarquistas - a médica pediatra Amparo Poch y Gascón (1902"1968), a advogada Mercedes 
${ }^{11}$ Lucía SAORNIL citada por Mary NASH, 1977, p. 62.

${ }^{12} \mathrm{NASH}, 1999$, p. 128.
Comaposada (1901"1994) e a poetisa Lucía SanchezSa ormil (1895"1970), todas militantes da Confederação Nacional do Trabalho - CNT, também de orientação libertária. Forma da em a bril de 1936, poucos meses a ntes da ec losão tanto da guerra civil, deflagrada pelas tropas do general Francisco Franco contra as forças populares, como da revolução social, que explode concomitantemente, a organização Mujeres Libres propôs-se lutar pela emancipação das mulheres espanholas, vítimas da ignorância, da opressão do Estado e da igreja e, não raro, de suas próprias famílias. Como a firmava Lucía Sanchez Sa ornil:

Propus-me abrir para a mulher as perspectivas de nossa revolução, oferecendo-lhe elementos para que forme uma mentalidade livre, capaz de discemir por si mesma o falso do verdadeiro, o político do social. Porque creio que mais urgente que estar organizada nos sindicatos, - sem que desd enhe esse trabalho -, é pô-la em condições de compreender a necessidade desta organização. ${ }^{11}$

Extrema mente a gilizada, a organização, em poucos meses, alcança uma ampla adesão das mulheres, espalhando-se portoda a Espanha e reunindo um número considerável de militantes. Algumas historia dora s estimam que tenha atingido até cerca de 30 ou 40 mil afiliadas. ${ }^{12}$ Além das fundadoras, inúmeras figuras, das qua is desta co apenas algumas, ajudam a compor um mosa ic o bastante multifacetado de militantes a inda a ser mais pesquisa do: Lola Iturbe (1902"1990), que assina como Kyralina osa rtigos que publica; Soledad Storach, uma das pioneiras do grupo cultural feminino CNT, de Ba rc elona, cria do em 1934; Sa ra Berenguer (Barcelona, 1919), que entrevistei em sua residência em Béziers, no Sul da França, em 2001; Concha Perez (Barc elona, 1915); Suceso Porta les, ta mbém na scida em meio operário, oradora; Pura Pérez Benavent (Valência, 1919; Ontário, 1995), que estuda na escola racionalista barcelonesa Natura; Pilar Grangel, professora racionalista e militante da CNT; Aurea Cuadrado; Conchita Guillén; Concha Gil; Pepita Struch Pons, que encontrei pela primeira vez na Federación Libertaria Argentina - FLA em sua visita a os companheiros de Buenos Aires, em 2000, e, um ano depois, em casa de Sara Berenguer; Maria Rodriguez Gil; Antonia Fontanillas, hoje com 90 anos, nascida num bairro popularde Barcelona e posteriormente exilada na França, que visitei várias vezes em Dreux e que se tomou o meu principal contato com esse passado; Maruja Lara, que entrevistei em sua casa, em Valência, em 2004; a alemã Etta Federn; Dolores Prat; Jeannette Hardy, que também assina os artigos da revista; Maria Duran (Barcelona, 
13 Murray BOOKCHIN, 2000; e Bumet BOLOTEN, 1997.

${ }^{14}$ Gerald BRENAN, 2000.

${ }^{15}$ Vejam-se três obras fundamentais sobre o tema da autogestão na Espanha: José PEIRATS, 1978; Franz MINTZ, 1977; e Walter BERNEC KER, 1982

16 Federica MONTSENY, 1987, p. 94.
1912"1995), que se exilou no Brasil e sobre a qual não conseg ui ma is informa ções a té o momento.

Esse rá pido crescimento, que lhes permite, a liás, criar uma federação nacional de Mujeres Libres, um a no depois, explica-se em grande parte pelo contexto revolucionário que a gitou a Espanha nesse período. Profundamente dilacerada e dividida ao meio por intensas lutas entre grupos políticos radicais, da esquerda e da direita, os espanhóis tiveram de enfrentarainda a ameaça do inimigo extemo, isto é, os fascista saliados. Contudo, foi nesse contexto que uma explosão revolucionária transformou radicalmente a vida social em amplas dimensões. ${ }^{13}$

Embora a historiografia sobre a Guerra Civil espanhola seja imensa, grande parte foi escrita por comunistas ou liberais, o que significa que muito pouco espaço foi destinado à revolução social e ao movimento autogestioná rio que marca a história desse país entre 1936 e 1939. Em meio à luta contra o fasc ismo interna cionalmente articula do e contra a inva sã o das tropas moura se do exérc ito espanhol, liderado pelo general Franco, eclode uma das ma is importa ntes experiênc ias de transfo ma ção ra dical da vida social, de reorg a nização das rela ções produtiva se de distribuição das riqueza s. ${ }^{14}$ Coletivizam-se as fábricas, desa propriam-se as terra s, a bole-se o dinheiro e formam-se conselhos operá rios que passam a gerir libertariamente a vida econômica e social. ${ }^{15}$ Desde as indústria smeta lúrgicas à sfa rma cêuticas, daspa da rias, dos resta ura ntes, dos hotéis e doscabeleireiros a os bondese ônibus, tudo é coloca do a serviço do povo, organiza do pelo poderconselhista. Como constata, em suas memórias, a líder anarquista Federica Montseny (1905"1994), que se tomaria paradoxalmente ministra da Saúde e da Assistência Social no governo de frente comandado pelo socialista Francisco Largo Caballero, em 1936:

Há que destacar, acima de tudo, as Coletivizações, pela importância que tiveram e porque, de fato, é o que fica e ficará, historicamente, da Revolução Espanhola. Isto é, a iniciativa e a inteligência dos operários que, poucos dias depois do triunfo sobre 0 fascismo, a briram asfábricas, ofic inase diversoscentros de produção, nomearam Comitês de Fábrica e puseram em marcha as máquinas, não permitindo que se interrompesse, porcausa da fuga dos patrões, a vida econômica. De uma economia que, de particular, passou a ser coletiva. O capitalismo desapareceu, de fato, e foi substituído pela organização de trabalho sobre bases novas demonstrando a capacidade construtiva e organizadora dos trabalhadores. ${ }^{16}$ 
${ }^{17}$ Agustín SOUCHY BAUER, 1977, p. 14.

${ }^{18}$ Nildo AVEUNO, 2006, p. 185.

19 Martha ACKELSBERG, 1991; J esuS BARRADOS, 2003; e Marga reth RAGO, 2004.

${ }^{20}$ Sara BERENGUER, 1988, p. 204.
Com cerca de dois milhões de afiliados, a CNT, a que estiveram ligadas as ativistas do Mujeres Libres, teve intensa partic ipação no processo de coletivização e de reorganização do trabalho e da vida social. Foram criadas cerca de 500 coletivida des, no Levante; 300 , na Ca ta lunha; 450, em Aragão; 250, em Castilha Nova. Nas localidades rura is de Aragão - cerca de 510 "pueblos" e cidades-meio milhão de habitantes participaram do processo de transformação da propriedade privada em propriedade coletiva. ${ }^{17}$ Essa coletivizaçã o nã o era nem imposta pelo Esta do, como fora na Rússia, nem existia um plano definido para as coletivizações, já que se pautava pelo princípio da autogestão. Contou, a inda, com o a poio dos téc nic os a ntifa s-c ista s estrangeiros e espanhóis, o que possibilitou o cresci-mento da produção, a o contrário do que se poderia ima ginar. ${ }^{18}$

É, portanto, nesse contexto de imensas esperanças revolucionárias, de crença na possibilidade de criarnovos universos sociais, polític os e culturais, de apostas nos princípios da solidarieda de e da liberdade como nortea doresda ação, de mudança dospadrões mora is, das relações de gênero e de quebra dos preconceitos herdados do passa do, que emerge esse grupo político ana rc ofeminista. ${ }^{19}$

Suas frentes de a tua ção foram inúmeras, do traba lho à saúde, da educação à morale à questão da subjetividade. Cursos de capacitação para as operárias, cursos de a lfa betização, c rec hes, centros de cultura pa ra a reflexã o e o conhecimento das questões femininas e para a difusão dos id ea is lib ertá rios fora $m$ a lvos imedia tos. Além do instituto Mujeres Libres e das centenas de agrupamentos loca is espalhados pelo país, elas fundam o "Casal de la Dona Traballadora", no Paseo de Gracia, em Barcelona, espaço cultural destinado aos cursos, às palestras e às oficinas realizados para cerca de 600 mulheres. Segundo as memórias de Sara Berenguer:

Neste local, desenvolvia-se um trabalho de capacitação imediata da mulher, com cursos elementares: aprender a ler, escrever, noções de aritmética, gramática e ciências naturais. Com cursos complementares de história universal, francês, russo, inglês, mecanografia, taquigrafia e cursos profissiona is complementares. ${ }^{20}$

Ofereciam, a inda, cursos de enfermagem, puericultura, com está g ios em hospita is e lug a res a dequados, mecânic a, eletric ida de, comérc io, corte e costura, noções de a gric ultura e avicultura. Ehavia os cursos dedic a dosà forma ção social, cursos de organização sindical, Sociologia, noções de Ec onomia e conferências semana is de a mp liação de cultura geral. O grupo criou uma revista anarc ofeminista, ta mbém \\ 194 Estud os Feministas, Floria nópolis, 16(1): 187-206, ja neiro-a b ril/2008}


${ }^{21}$ Carta de Mujeres Libres a Hemandez Domenech, 27 maio 1936.

${ }^{22} \mathrm{NASH}, 1999$, p. 143.

${ }^{23} \mathrm{~J}$ a vier NAVARRO, 2004. chamada Mujeres Libres, redigida a penaspormulheres, pois, diziam elas, "sabemos por experiência que os homens, por muito boa vontade que tenham, dificilmente a tinam com o tom preciso". ${ }^{21} \mathrm{Em}$ relação à prostituição, Mujeres Libres defendeu a criação de "libera tórios de la prostituc ión", isto é, abrigos para as prostitutas que procurassem outras altemativas de vida. Finalmente, pressionou os dirigentes políticos por transformações na área da saúde e da educação, de modo mais amplo. Vale lembrar que, em dezembro de 1936, o aborto foi legalizado na Catalunha, porobra da ministra Federica Montseny, a lia da, embora não participante do grupo. ${ }^{22}$

Anarquistas, as três principa is fundadoras haviam concluído que, mesmo nos meios sind ic a is libertá rios que freqüentavam, havia pouco espaço para as questões específic as das mulheres. Emesmo que não se chamassem de feministas, já que identific a va m como feminista sa quelas que luta va $m$ a penas pelo direito de voto, sem questiona $\mathrm{r} o$ Esta do e a própria cond ição feminina, tiveram uma a tuação feminista radicalmente transformadora nas questões da sexualida de, da saúde, da educação, do trabalho feminino e fundamentalmente nas próprias interpretações que construíram de seu mundo.

A pesquisa sobre esse grup o revolucioná rio leva-me a perguntar pelas "estétic as da existência" que praticaram, norteadas pelos princípios a narquistas e pelos feministas, ao longo dos três anos de duração da experiência revolucionária, curto-circuitada pela instalação da ditadura de Franco, em 1939. Mas, vale lembra rque, desde suas origens no século 19, a formação de um novo serhumano - o "novo homem" e a "nova mulher" - foi um tema recorrente dessas doutrinas, que entendiam que somos produtos históricos, soc ia is e cultura is. Os a na rquistas, em especial, investiram fortemente na educação, fundando "escolas modemas", a teneus, centros de cultura, grupos artístic os, inclusive no Bra sil, entend end o que esses seria m os princ ipa is meios pa ra criar novos indivíduos, amantes da liberdade, críticos do poder, da dominação e das injustiças sociais. ${ }^{23}$

Mujeres Lib res lutou a tiva mente para que as mulheres se autonomizassem, não apenas economicamente, mas também psiquicamente, e é aqui que meu interesse pelo grupo se reforça. Compreendeu nitidamente que, muitas vezes, o pior inimigo se encontra va em casa, na figura do pai, irmão ou marido, o que tornava a luta pela emancipação feminina muito ma is difíc il e complexa. Assim, assinando o artigo "A dupla luta da mulher", na revista Mujeres Libres, a milita nte llse a firma va que, a o contrá rio do homem revolucioná rio, que em sua luta enfrenta o mundo exterior,

Estudos Feministas, Floria nópolis, 16(1): 187-206, janeiro-abril/2008 195 
${ }^{24}$ Revista Mujeres Libres, n. 7, p. 4, VIII mês da Revolução.

${ }^{25}$ Revista Mujeres Libres, n. 7, p. 4, VIII mês da Revolução.

${ }^{26}$ J omal Solidaridad Obrera, 15 out. 1935.

${ }^{27}$ Editorial. Mujeres Libres, n. 7, p. 1, VIII mês da Revolução.
A mulher revolucionária, em troca, tem de lutar em dois terrenos: primeiro, por sua liberdade exterior, em cuja luta tem no homem um aliado pelos mesmos ideais, por causa idêntica; porém, ademais, a mulher tem de lutar pela própria liberdade interior, desta que o homem desfruta há séculos. E, nesta luta, a mulher está sozinha. [...] a mulher que quer emancipar-se na igualdade de direitos, tem de empreender primeiro a luta em seu próprio campo. E nesta luta, ademais de encontrar-se só, ademais de contar unicamente consigo mesma, dificulta-lhe a luta do inimigo que reside em seu próprio campo, um inimigo a quem nunca reconheceu conscientemente como tal, a quem está ligada intimamente e por instinto desde sua primeira infância. ${ }^{24}$

Segundo ela, eram enormes as dificuldades para rompercom a família e a tra dição, com tudo o que reprime sua personalidade, pois

é difícil lutarc ontra entes queridos que a querem induzir à espera passiva e virginal do homem que lhe ofereça o matrimônio e the assegure uma existência na qual a mulher, cheia de ignorância e preconceitos, não consegue encontrar a felicidade, mas sim uma vida desola da e triste. [...] Nessas circ unstâncias, a liberda de interior era impossível. ${ }^{25}$

Lucía Sanchez Sa ornil, por sua vez, questionando a teoria da diferenciação sexual, segund o a qual as mulheres nasceram para ser mães, indignava-se com a pressão exercida para realiza rem-se a penas na matemidade. Essa insistência é denuncia da em muitos dos seus textos, como o que aparece publicado no jornal libertário Solidaridad Obrera, anosantes:

Antes se exaltava a mãe prolífica, parideira de heróis, de santos, redentores ou tiranos; de agora em diante, se exaltará a mãe eugenista, a engendradora, a gestadora, a parideira perfeita. [...] Agora temos algo pior: o conceito de mãe absorvendo o de mulher, a função a nulando 0 indivíd uo. ${ }^{26}$

Na mesma direção, investindo contra a ideologia da domesticidade e colocando-se contra o individua lismo doméstico e familiar, no artigo "Mujeres!", o editorial da revista Mujeres Libres a firmava:

Temos dito que "o lar" era, na maioria dos casos, um símbolo da escravidão. [...] Trata-se de que todas as mulheres saiam de sua dependência, de seu "lar", de sua própria vida. [...] De que todasas mulheres formem unidade feminina de triunfo e progresso. ${ }^{27}$ 
${ }^{28}$ SAORNIL citada porNASH, 1977, p. 60.

${ }^{29}$ Revista Mujeres Libres, n. 9, XI mês da Revolução.

\section{A moral sexual}

A crítica a o confinamento das mulheres no privado estendeu-se também à experiência sexual, já que os anarquistas defendiam a liberdade sexual para todas/os. Num a rtigo polêmic 0 , Lucía questionava a idéia de divulgarse o amor livre entre as jovens, sem um trabalho de prepa ra ção cultural e étic a anterior; sem desfazerem-se os preconceitos que as jovens traziam em seus espíritos. Critic ava a lguns a na rquista s por entra rem como "Don J uans" e "Otelos", aproveitando-se de sua ingenuidade e acabando pordecepcioná-lase a fastá-las. "Valeria a pena encomendar a orientação sexual de nossas juventudes a conferencistas capacitados nas matérias que Ihes assina la ram $[\ldots . .]^{\prime \prime}{ }^{28}$

No artigo "O problema sexual e a Revolução", assina do pela redação da revista Mujeres Libres, da qual Lucía fazia parte, afirmava-se o objetivo de se registrar a reação diferenciada diante da questão sexual que manifestaram homens e mulheres durante o processo revolucionário. Contava-se que, antes do movimento de julho, já se vinha desenvolvendo, partic ula mente nosmeios operários, uma intensa campanha de "educação sexual", em que se havia enfatizado demais o tema da liberdade sexual da mulher, sem trabalhá-lo suficientemente. Como resultado, registraram-se efeitos contrá rios ao que se esperava. A guerra havia levado muitas mulheres às ruas para prostituírem-se porfalta de trabalho, enqua nto muitos jovens ma is ric os se lança va $m$ desenfrea da mente em busca de satisfação dos instintos. Mas, o movimento de julho deixara cla ro que a revolução social poderia trazera solução a o problema econômico, político e sexual.

Propunha-se para o problema da prostituição a criação de "libera tórios da prostituição", c omo um palia tivo e não solução, considerando que o problema se tomara mais agudo com a guerra. E afirmava-se que qualquer instituição para a capacitação da mulher seria, ma is do que um "libera tório", um preventivo da prostituição. ${ }^{29}$

Esse é, a liás, um tema de destaque no universo de preocupações do Mujeres Libres. Em vários a rtigos public a dos na revista, critic a va-se a visão estreita de que a prostituição seria apenas sexual, já que todos os trabalha dores vendem o próprio corpo. Denuncia va-se ta nto a polícia quanto a polític a do regulamentarismo, segundo a qual as prostitutas deveriam ser fic ha da s pelo Esta do e a própria atividade de comercialização do sexo deveria ser supervisionada pelo Estado. Defendia-se a supressão da prostituição ao mesmo tempo que era proposta a organização dos liberatórios. Nesses, deveria haver 
${ }^{30}$ Revista Mujeres Libres, 65 dias da Revolução.

${ }^{31}$ SAORNIL, 1937, p. 26. investigação e trata mento médico-psiquiátrico, cura psicológica e ética para fomentar nas alunas um sentido de responsabilidade; orientação e capacitação profissional; ajuda material e moral em qualquer momento, mesmo que a mulher já tenha se independentizado do libera tório. ${ }^{30}$

Criticavam-se os companheiros que recorriam às prostitutas, já que não ajudavam na obra de erradicação dessa "degradação social", a ssim como as pretensas novas a titudes dos companheiros.

Feminista radical, Lucía faz contundentes questionamentos nos textos que compõem o seu livro Horas de Revolución, public ado em 1937. Ao criticar os casamentos que passa vam a se rea liza rnos sind ic a tos, por destruírem a idéia de a mor livre, ela a firmava:

Se a Revolução é reforma de costumes, comecemos por aí; mas logo, rapidamente, pratiquemos tudo o que ontem constituía nossas aspirações, nossa lei e nossos princípios.

Dissemos num outro dia que a Revolução devia começar em nós mesmos, e se não o fazemos, perderemos a Revolução social, nem mais, nem menos; nossa mentalidade burguesa não fará mais do que revestir de roupas novas os velhos conceitos, conservando-os em toda sua integridade.

É preciso tomar cuidado com essas pequenas coisas (refere-se ao aumento de casamentos nos sindicatos), que às vezes, são os melhores delatores de nossa falta de capacidade revolucionária.

Condenemos, se nos agrada, a liberdade de união; mas não a disfa rcemos covardemente com hipócritas cerimônias, mesclando os Sindicatos em nossas covardias espiritua is. ${ }^{31}$

O amorlivre sempre foi uma importante bandeira das lutas ana rquistas, contraposto à idéia do casamento monogâmico indissolúvel, do contra to burguês de casamento e da dupla moral sexual, que exigia virginda de e castidade para as mulheres, enquanto aos homens caberia toda a liberdade sexual desejada. Já desde os a nos vinte, no Brasil, a libertária Maria Lacerda de Moura escrevia os seus conhecidos ensaios, em que defendia o "amor plural", baseando-se nasconcepções de Han Ryner. ${ }^{32}$ Na Espanha, publicou váriosartigos na revista Estudios, nos a nos trinta, polemiza ndo com as noções sexua is correntes.

A doutora Amparo Poch y Gascón também defendia abertamente a liberdade de amar para as mulheres, denunciando as imposições mora is patriarcais ou partidá rias. ${ }^{33}$ Afirma va suas concepções libertá rias em vá rios textos, dos quais destaco seu "Elogio do amor libre",34 
${ }^{35}$ Revista Mujeres Libres, Madri, $n$. 3, p. 12, jul. 1936, citada por RAGO, Margateth; BAJOU, Maria Clara Pivato. Mujeres Libres da Espanha: Documentos da Revolução Espanhola. Rio de Janeiro: Achiamé, 2008. p. 86. publicado na revista, que surpreende não só pelas idéias a va nç a das e ousa das, mas pela qua lida de literá ria. Nesse texto, Amparo parte em defesa do que considera o "bom a mor" e procura incentivar as mulheres a a marem de uma outra maneira, livres, sem sub meterem-se aoscód ig os mora is dominantes. $O$ texto é composto de oito exc ertos, a começar por "Elog io do a mor livre", passando por "Inc itaçã o a o bom amor", "Matrimônio e amor", "Um fruto esplêndido: o a dultério", "A mulherem defesa", "A c a minho do bom a mor", "Amor livre!" e "Remessa". Logo no primeiro item, meta foriza sua crítica à vida sedentária do casal estabilizado, a firma ndo não possuire não querer ter uma casa, mas, a o contrá rio, possuir um teto para recebero a mado e protegêlo da chuva, com as mãos abertas para "incontá veis carícias". Diz ela:

II - Não tenho Casa. Tenho, sim, um teto a mável para resguardá-lo da chuva e um leito para que você descanse e me fale de amor. Mas não tenho Casa. Não quero! Não quero a insaciável ventosa que enfraquece o Pensamento, absorve a Vontade, mata o Sonho, rompe a doce linha da Paz e do Amor. Eu não tenho Casa. Quero amar no extenso "além" que não fecha nenhum muro nem limita nenhum egoísmo. III - Meu coração é uma rosa de carne. Em cada folha há uma temura e uma ansiedade. Não o mutile! Tenho asas para ascender pelas regiões da pesquisa e o trabalho. Não as corte!

Tenho as mãos como palmas abertas para recolher moedas incontá veis de carícias. Não as acorrente! $[\ldots]^{35}$

No segund o exc erto, "Inc ita ção a o bom a mor", dirigese à mulher incentivando-a a a mar livremente:

Mulher, a me sobre todas as coisas. Mas antes a prenda o Bom Amor. No Bom Amor pesa tanto o alto como o baixo, o Pensamento como a Came, a Doçura como o Desejo; e é incompleto se lhe falta qualquer uma dessas coisas. Aprenda o Bom Amor.

Para ele, necessita-se de plena liberdade, mas também capacidade plena, pois sem esta a primeira é uma ficção. Só se é livre quando se pode tomar uma decisão dentre as que a ocasião oferece; quando se pode eleger um caminho depois de ter reconhecido todos, pesando seus valores e aceitando suas conseqüências. Mas isto é obra da Inteligência, do Coração e da Vontade, e é preciso aperfeiçoar os três se queremos alcançar a categoria dos seres livres. Se não for assim, seguiremos afogando a nossa inquietude entre simulacros amorosos.

Se você não se capacita, mulher, será um ser de instintos, será uma came simples, monótona e limitada, 
${ }^{36}$ Revista Mujeres Libres, Madri, $n$. 3, p. 12, jul. 1936, citada por RAGO, Margateth; BAJ OU, Maria Clara Pivato. Mujeres Libres da Espanha: Documentos da Revolução Espanhola. Rio de Janeiro: Achiamé, 2008. p. 86.
${ }^{37}$ Revista Mujeres Libres, Madri, $n$. 3, p. 12, jul. 1936, citada por RAGO, Margateth; BAJOU, Maria Clara Pivato. Mujeres Libres da Espanha: Documentos da Revolução Espanhola. Rio de Janeiro: Achiamé, 2008. p. 86.
${ }^{38}$ Revista Mujeres Libres, Madri, $n$. 3, p. 12, jul. 1936, citada por RAGO, Margateth; BAJ OL, Maria Clara Pivato. Mujeres Libres da Espanha: Documentos da Revolução Espanhola. Rio de Janeiro: Achiamé, 2008. p. 86. fechada em si mesma e por si mesma abolida. Se não se capacita, você poderá vibrar com o ritmo irregular das estações e dos dias nublados seguidos de sol forte; terá a pulsação perene dosanima is e das plantas; dará suas generosas florações de fêmea; porém, não conseguirá o Bom Amor.

[...] Mulher, ame sobre todas as coisas. ${ }^{36}$

Ao abordaro tema do "Ma trimônio e amor", considera que os homens condenaram Eros, "despoja do de suasasas", pela culpa, pela submissão à moral, pela invenção do casamento e da obrigação da procriação:

Do gesto amoroso, fez-se um minucioso código, morto e frio; do mais grato e ardente presente, uma compra e venda em parcelas, inclusive com sua regulamentação; ou à vista, com seu contra to em regra, e a um preço muito ma is elevado, porque a lém do dinheiro, que conta para muito pouco, entram em compromisso o Coração e a Liberdade, que são tudo para o Amor. ${ }^{37}$

Em seguida, tematiza "Um fruto esplêndido: o a dultério", mostrando que este resulta do próprio cerceamento da energia afetiva no casamento:

Assim, da degradante aceitação do matrimônio contrato e regulamentação do inalienável - surgiu esse fruto vermelho e redondo, farto e eloqüente, estupendo e prometedor: o adultério. É o protesto natural e humano contra a trava pesada ao alado e imponderável; e reivindica, como uma gargalhada fresca, entre zombeteira e honrada, o pleno direito à liberdade de amaro transbordamento sobre todas as correntezas artificiais, da evolução da personalidade. Aqui está, como uma conseqüência do esquecimento do verdadeiro ser de Eros e do Homem, este duplo crime da mísera vida diária: a convivência fria ou a carícia instintiva e isolada sobre a Came muda; e o abandono culpado e temeroso do Sentimento, valor universal. Em suma, amor que não é Amor. ${ }^{38}$

Logo, defende a liberdade de amarpara asmulheres, livre da submissão a o poder masculino, que a transforma em propriedade pessoal e incita a que se prepare para o "Bom a mor", sem as exigências tra dic iona is:

Mulher, se quer recobrara dignidade perdida; se quer encontrar um sol novo neste sol tão antigo; se quer sentir o relaciona mento de sua a Ima e a graça singular de encontrar-se a si mesma, ascender pela escada a morosa a mercê de sua superação. Multiplique sua capacidade de amor, mulher, mas [...] Pense que o sentimento também não lhe dá direito sobre ninguém, nem a faz objeto de propriedade. 
${ }^{39}$ Revista Mujeres Libres, Madri, $\mathrm{n}$. 3, p. 13, jul. 1936, citada por RAGO, Margateth; BAJOU, Maria Clara Pivato. Mujeres Libres da Espanha: Documentos da Revolução Espanhola. Rio de Janeiro: Achia mé, 2008. p. 89.
${ }^{40}$ Revista Mujeres Libres, Madri, $n$. 3, p. 13, jul. 1936, citada por RAGO, Margateth; BAJOU, Maria Clara Pivato. Mujeres Libres da Espanha: Documentos da Revolução Espanhola. Rio de Janeiro: Achiamé, 2008. p. 90.

${ }^{41}$ RAGO, 2001
Pense que, pormaiores que sejam a paixã o do prazer e o prazer da paixão, não devem arrastá-la em sua torrente; e que, se em uma hora gloriosa, extraviar seus sentidos, jama is deve perder sua própria vonta de $[\ldots] .^{39}$

Ao falar do "Amor livre", sugere à mulher reinventa rse:

E então, mulher, apaixonadamente enamorada, não peça nada por seu amor. Semeie-o, como a vida; faça-o florescer, como a roseira; levante-o, como o eucalipto; sem perguntar nada, sem pedir nada para a manhã .

Nem a videira, nem a roseira, nem o eucalipto, antes de granar, antes de florescer, antes de se levantar, pedem um jardineiro que os atenda; nem exigem promessa de que o sol não haverá de secá-los, nem o vento haverá de quebrar seus talos, nem a água impetuosa haverá de afogar suas raízes. Eles são generosos e quando um deles perece, muitos ma is nascem para a vida. Ame, ame, mas que os braços não lhe sirvam como amarras, mas como coroa. Deixe que tudo vá e venha, e você, sorria sempre, tenaz procuradora de todas as alegrias terrenas. Sorria sempre, ágil e sentimental, doce e reflexiva, através do esquecimento, do desprezo, da crítica. Alente sua criação: lance à Vida um novo módulo para a valorização de seu sexo. [...]

Crie o novo tipo; ponha sal na Vida; cor e chama em beijos desiguais. Ame, fale, trabalhe. Compreenda, ajude, console.

Aprenda a desaparecer e a desobrigar de sua presença; e a conhecer o valor do "eu" livre. Sem nada; nem por dinheiro, nem por paz, nem por sossego [...] Amor Livre! ${ }^{40}$

Ta mbém aqui é preciso contextua liza r historic a mente essa s o usa das a firma ções do Mujeres Libres, que não brotam espontaneamente, pois, mais do que em qualquer outro país, a cultura anarquista espanhola estabeleceu-se fortemente e contou com vá ria soutra sa desões, como a dos médicos e psiquiatras libertários. ${ }^{41}$ Médicos como Isaac Puente, preso logo que eclode a Guerra Civil, em 1936, fuzila do pelos franquistas, ou Felix Martí lbañez e a própria Amparo Poch y Gascón que lutaram intensamente pela transformação da moral sexual conserva dora e preconceituosa. Vale recorrer a os depoimentos da dos pela já cita da anarquista Antonia Fontanillas. Diz ela em gravação de 1996:

Desde 1904 ou 1905, começou a penetrar em Barcelona a corrente neomaltusiana, iniciada na França, por Paul Robin, através da revista e de 
42 FONTANILLAS, Antonia. "Do a prendid o e do vivido". In: RAGO, Margareth; BIAJOL, Maria Clara Piva to. Mujeres Libres da Espanha: Documentos da Revolução Espanhola. Rio de Janeiro: Achia mé, 2008. p. 121. Entrevista concedida em 1996.

43 FO NTANILLAS, Antonia. "Do a prendido e do vivid o". In: RAGO, Margareth; BIAJOL, Maria Clara Piva to. Mujeres Libres da Espanha: Documentos da Revolução Espanhola. Rio de Janeiro: Achiamé, 2008. p. 121. Entrevista concedida em 1996. publicações como "Salud y Fuerza" [...]. Propugnavase, pois, a maternidade consciente e limitada e ilustrava-se sobre os meios de evitar a gravidez. Essa corrente foi-se ampliando, tomando-se mais variada e sugestiva com o aparecimento em Alcoy, em 1923, da eclética e bela revista "Generación Consciente", da qual foi nervo, junto ao seu editor Luis Pastor, o incomparável doutor Isaac Puente, mais conhecido talvez por seu tão divulgado folheto "El Comunismo Libertario". Ele foi o motor dessa revista, colaborando em todos os números com dois ou três artigos, com seu próprio nome ou como "Um médico rural". Artigos científicos ou dedicados à mulher, contracepção, amor, sexo, temas socia is. Nós, mulheres, devemos reconhecer o que trouxeram à nossa cultura, à nossa própria formação, os conhecimentos desses homens que nos reconheceram e batalharam também por nossos direitos. [...]. Outro jovem daquela época, abordando temas parecidos e mais especializados em psico-sexualidade foi o jovem e culto doutor Felix Martí lbañez. J ovem e para a juventude, escreveu uma novela estupenda, a que mais me impactou, "Yo rebelde". É sobre o tema da juventude, que busca um sentido para sua vida. ${ }^{42}$

Contudo, ta mbém é preciso considerar que as propostas ra dic a is d esses a na rquistas, a ssim como do Mujeres Libres, não eram a mpla mente pratic a das ou a c eitas. Sobre a experiência de vida dos anarquistas, falando do início do século, Fonta nilla s a firma que, embora seuspa is tivessem praticado a união livre, em relação aos filhos, mostra vamse maisconservadores:

A educação sexual não era um tema que meus pais abordassem. Com mamãe, não era possível comunicar-se muito, porque além do mais, foi fic ando surda como meu avô. Porém, na biblioteca de papai, havia de tudo, não apenas Sociologia ou doutrina. Recordo que, aos 14 anos, chamou-me a atenção um livro que ainda tenho em casa: Lo que todos deverían saber (La iniciación sexual) de G. M. Besséde. Obra muito instrutiva, que reflete as conversas dos pais com seus filhos, meninos ou meninas, dos 3 aos 20 anos. Emprestei-o a uma companheira de classe, maior do que eu, que me devolveu dizendo: "Por que você lê isto?" Como se fosse um tabu.

Embora ele só chegasse a uma minoria, temos de reconhecer que à mulher ou à moça que tivesse um mínimo de instrução, quer dizer, que soubesse ler e que tivesse um espírito desperto e curioso, não faltavam oportunidades para auto-educar-se, para c ultivar seu espírito e a mpliar seus c onhecimentos, seja freqüentando os a teneus, cursos, conferências, tea tro, excursões, etc., e instruindo-se a tra vés da leitura. ${ }^{43}$ 
${ }^{44}$ Bert HOFMAN, Pere J oan TOUSe Manfred TIETZ, 1995, p. 289.

45 Revista Estudios, n. 94

${ }^{46}$ Isa a c Puente ta mbém assina va como "Um médico rural". Ver "A modo de programa". Estudios, jun. 1931. E também Generación Consciente, 1923.

${ }^{47}$ NASH, Mary. "La Reforma Sexual en el anarquismo español". In: HOFMANN, Bert; TOUS, Pere Joan; TIETZ, Manfred (Eds.). El anarquismo espanhol y sus tra diciones culturales. Frankfurt am Main: Vervuert; Madrid: Iberoamericana, 1995. p. 291.

${ }^{48}$ Para essa discussã o, veja-se Rosi BRAIDOTTI, 2000.
As militantes aqui consideradas não estavam iso la das em suas a ná lises e reivind ic ações, esp ecia Imente no que concerne à moral sexual. Desde os anos vinte, por exemp lo, a revista Generación Consciente tra zia artig os sobre a maternidade, difundia o ideal do neomalthusianismo, o controle da natalidade e outras questões eugênicas; e, portanto, dava atenção especial à mulher, considerada responsável pela regeneração física e moral do proletariado. Sua sucessora, a revista mensal Estudios, que teve 102 números publicados, entre 1928-1937, possuía uma seção intitula da "Consultório psic ossexual", em que o Doutor Ibáñez, especialista em Psicologia sexual e em Sexologia, respondia às cartas dos trabalhadores. Procurava apresentar soluções para os problemas a presenta dos pelos/as leito res/a se prestar esc la rec imentos so bre os distúrb iosfísic os, sexua is e psicológicos.

Segundo Mary Nash, ${ }^{44}$ a discussão sobre a sexualidade e o a cesso popular a os conhecimentos científicos que se difundiam em plano intemacional inclusive era $\mathrm{m}$ fa vorecid os pelos a na rquistas, que a c red ita va $\mathrm{m}$ sera sexologia fundamental para a formação integral do ser humano. Como dizia a revista Estud ios, ${ }^{45}$ em junho de 1931: "Não concebemos progresso humano que não esteja baseado na auto-educação, quer dizer, na ação modela dora de cada um sobre si mesmo". ${ }^{46}$ Portanto, sexualidade e subjetividade aparecem estreitamente conectadas no discurso anarquista. Aliás, "a construção do discurso da sexualidade no anarquismo espanhol se fundamenta na elaboração de uma nova ética", conclui Nash. ${ }^{47}$

\section{Cuidado de si, cuidado do outro}

São muitasas dimensões em que se podem encontrar práticas feministas libertá rias postas em ação pelo grupo visa ndo libertara smulheres da sujeição a o modelo burguês de feminilid a de e ind ic a r-lhes novos ca minhos de a uto no mia pessoal. E, porta nto, va leria esc la recerque as possibilida des abertas pelo grupo para constituírem-se subjetividades libertá rias não se efetiva ram num marco individualista. ${ }^{48}$ Essas possibilidades visavam a uma intensific ação das relações consigo mesma, mas não no sentido de uma valoriza ção da vida privada em detrimento da pública, nem no de uma acentuação do valor do indivíduo sob reposto em relação a o grupo. Longe de estimularo a pego a o privado como refúg io em rela ção a o mundo competitivo dosnegóciose da política, essa cultura de si do ana rcofeminismo propunha a criação de novas relações de si para consigo, mas ta mbém com o outro, relações solidá rias, de a mizade, de companheirismo político, anti-hierárquicas,

Estudos Feministas, Floria nópolis, 16(1): 187-206, ja neiro-abril/2008 203 
num meio sofrid o como o do operário. Visa va, a inda, fortaleceras redes da militância política, tanto entre elas mesmas como com os companheiros ligados a outras entidades, sobretudo nesse momento de intensa movimenta ção revolucionária em que um novo mundo parecia totalmente possível.

\section{Referências bibliográfic as}

ACKELSBERG, Martha. Free Women in Spain. Ana rchism and the Struggle for the Emancipation of Women. Indianopolis: Indiana University Press, 1991.

AVELINO, Nildo. "A constituição de si na experiência da Revolução Espanhola (1936-1939)". Verve, NU-SOL Programa de Pós-Graduação em Ciências Sociais da PUC-SP, n. 10, p. 183-204, 2006.

BARRADOS, J esus M. Montero. Ana rc o-feminismo em España. La revista Mujeres Libres antes de la Guerra Civil. Madrid: Fundación Anselmo Lorenzo, 2003.

BERENGUER, Sara. Entre el Sol y la tormenta. Treinta y dos meses de guerra (1936-1939). Barcelona: Seuba Ediciones, 1988.

BERNEC KER, Walter. Colectividades y revolución social. El anarquismo en la Guerra Civil española, 1936-1939. Ba rcelona: Ed itorial Critica, 1982.

BIAJOL, Maria Clara Pivato. "Sem regras nem disciplina: a escrita feminista das mulheres a na rquista s espanholas". Labrys, jan.-jun. 2007. Disponível em: http://www.unb.br/ ih/his/gefem/. Ac esso em: fev. 2008.

BOLOTEN, Burnet. La Guerra Civil Española. Revolución y contra revolución. 2. ed. Madrid: Alianza Editorial, 1997.

BOOKC HIN, Murra y. Los ana rquistas españoles en los heroicos 1868"1936. Valencia: Numa Ediciones, 2000.

BRAIDOTT, Rosi. Sujetos nóma des. Buenos Aires: Paidos, 2000.

BRENAN, Gerald. The Spanish Labyrinth. Cambridge: Cambridge University Press, 2000.

FONTANILAS, Antonia. "Do a prendid o e do vivido". In: RAGO, Margareth; BIAJ OLI, Ma ria Clara Pivato. Mujeres Libres da Espanha: Documentos da Revolução Espanhola. Rio de Janeiro: Achiamé, 2008. p. 117-130. Entrevista concedida em 1996.

FOUC AULT, Michel. Dits et Éc rits. Pa ris: Gallima rd, 1994. T. II e T. IV.

. História da sexualidade. A vontade de saber. Rio de Janeiro, Graal, 1977. v. 1.

. História da sexualidade. 0 uso dos prazeres. Rio de Janeiro: Graal, 1985a.

- História da sexualidade. O cuidado de si. Rio de Janeiro: Graal, 1985b. 

2004.

A hermenêutic a do sujeito. Sã o Paulo: Martins Fontes,

GROS, Frédéric. "O cuidado de si em Michel Foucault". In: RAGO, Margareth; VEIGA NETO, Alfredo. Figuras de Fouc ault. Belo Horizonte: Autêntica, 2006. p. 125-138.

HOFMANN, Bert; TOUS, Pere Joan; TIETZ, Manfred (Eds.). El anarquismo espanhol y sus tradiciones culturales. Frankfurt am Main: Vervuert; Madrid: Iberoamericana, 1995.

Jomal Solidaridad Obrera. Órgano de la Confederación Regional del Trabajo de Cataluña. Barcelona, 15 out. 1935.

LEITE, Miriam Moreira. Maria Lacerda de Moura: o outro lado do feminismo. São Paulo: Martins Fontes, 1984.

MINTZ, Frank. La autogestión en la España Revolucionaria. Madrid: Ed ic iones de La Piqueta, 1977.

MONTSENY, Federica. Mis primeros cuarenta años. Barc elona: Plaza e J anes Editores S.A., 1987.

MURGEL, Ana Carolina de Toledo. "Entre Ca pitus, Gabrielas, Tigresase Ca rolinas: o olharfeminino na canção popular brasileira". Labrys, jan."jun. 2007. Disponível em: http:// www.unb.br/ih/his/gefem/. Acesso em: fev. 2008.

NASH, Mary. Rojas. Las mujeres republicanas en la Guerra Civil. Ba rcelona: Taurus, 1999.

(Org.). Mujeres libres: España, 1936"1939. Barcelona: Tusquets, 1977.

. "La reforma sexual en el a narquismo español". In: HOFMANN, Bert; TOUS, Pere J oan; TIETZ, Ma nfred (Ed s.). El anarquismo espanhol y sus tradiciones culturales. Frankfurt am Main: Vervuert; Madrid: Iberoamericana, 1995. p. 281-296.

NAVARRO, J a vier N. A la revolución por la cultura. Va lencia: Universitat de Valencia, 2004.

PEIRATS, José. La CNT en la Revolución Española. Madri: Ruedo lbéric 0, 1978. Tomo I.

RAG O, Marga reth. "Es que no es digna la satisfacción de los instintos sexuales? Amor, sexo e anarquia na Revolução Espanhola". In: SOARES, Carmen L. (Org.). Corpo e História. Campina s, SP: Editora Autores Associa dos, 2001. p. 145161.

"Mujeres libres: anarco-feminismo e subjetividade na Revoluçã o Espanhola". Verve, Sã o Pa ulo: NU-SOL, PUC SP, n. 7, p. 132-152, 2004.

RAGO, Marga reth; BIAJ OL, Maria Cla ra Piva to. Mujeres libres da Espanha: Documentos da Revolução Espanhola. Rio de Ja neiro: Achia mé, 2008.

Revista Mujeres Libres. Madrid, 1936-1939. 13 números.

Revista Estudios, Valência, 1929-1938. 
Revista Generación Consciente. Valência, año I, n. 1, jun. 1923.

RODRIGO, Antonina. Una mujer libre: Amparo Poch y Gascón, médica y a narquista. Barcelona: Ediciones Flor del Viento, 2002.

SAORNIL, Lucía Sanchez. Horas de Revolución. Barcelona: Edita do porel Sindic a to Únic o del Ramo de Alimentación de Barcelona, 1937.

SO UC HY BAUER, Agustín. Entre los campesinos de Aragon. El comunismo libertario en las comarcas liberadas. Ba rc elona: Tusquets Editor, 1977.

TVARDOVSKAS, Lua na Sa tumino. "Na tra nsversal. Três a rtistas brasileiras", Labrys, jan.-jun. 2007. Disponível em: http:// www.unb.br/ih/his/gefem/. Acesso em: fev. 2008.

[Recebido em ma io de 2006 e aceito para public ação em outubro de 2007]

New Modes of Subjectivation: the Experience of "Mujeres Libres" in the Spanish Revolution

Abstract This article focuses on the experience of one of the major mass women's movement during the Spanish Revolution, the a narchist and feminist organization "Free Women". Itconsiders Foucault's concepts as well as feminist critic ism relating to ethics and subjectivity as the main theoretic al references. In the context of a revolutionary movement, that started in Spain in the thirties, the organization aimed at achieving feminine emancipation. It understood clearly the importance of creating new modes of subjectivation, in this highly conservative, religious and male country.

Key Words: Feminism; Foucault; Anarchism; Aesthetic s of Existence; Ca re of the Self. 